\title{
ALFABETIZAÇÃO E DIALOGICIDADE FREIREANA: aprendizagens, sentidos e possibilidades
}

\author{
Leila Damiana Almeida dos Santos Souza \\ Kleber Peixoto de Soura
}

\section{Resumo}

Sendo a dialogicidade uma das principais categorias da educação libertadora de Paulo Freire, não é possível conceber o processo alfabetizador sem dar centralidade a capacidade que o mesmo tem de criticizar o debate de situações desafiadoras na práxis que envolve o aprender e o ensinar. Sendo assim, o presente artigo apresenta algumas reflexões sobre diferentes concepções de alfabetização que, por sua vez, nos permitirá instaurar uma espécie de roda dialógica com alguns autores e seus pressupostos teóricos. Objetivamos assim, criar um movimento onde os vários sentidos do termo alfabetização se confrontam e se completa, gerando uma perspectiva ampliada para esse processo múltiplo e singular. Metodologicamente, fizemos uma busca na literatura acerca dos processos de alfabetização, sobretudo os estudos de Magda Soares e também as intersecções de algumas concepções teóricas com a práxis alfabetizadora de Paulo Freire. Como resultado, esperamos que educadores possam se valer dos múltiplos sentidos (polissemia) que reveste o termo alfabetização.

Palavras-chave: alfabetizar; dialogia; letramento; polissemia.

\section{LITERACY AND FREIREAN DIALOGICITY:}

\section{learning, meanings and possibilities}

\begin{abstract}
Since dialogicity is one of the main categories of Paulo Freire's liberating education, it is not possible to conceive the literacy process without giving centrality to its capacity to criticize the debate of challenging situations in the praxis that involves learning and teaching. Thus, this article presents some reflections on different conceptions of literacy which, in turn, will allow us to establish a kind of dialogic wheel with some authors and their theoretical assumptions. Thus, our aim is to create a movement where the various meanings of the term literacy confront and complete each other, generating an expanded perspective for this multiple and singular process. Methodologically, we searched the literature about literacy processes, especially the studies by Magda Soares and also the intersections of some theoretical concepts with the literacy praxis of Paulo Freire. As a result, we hope that educators can make use of the multiple meanings (polysemy) that covers the term literacy.
\end{abstract}

Keywords: literate; dialogy; literacy; polysemy.

\section{ALFABETIZACIÓN Y DIALOGICIDAD FREIREANA:} aprendizaje, significados y posibilidades:

Resumen

Dado que la dialogicidad es una de las principales categorías de la educación liberadora de Paulo Freire, no es posible concebir el proceso de alfabetización sin darle centralidad a su capacidad de criticar el debate de situaciones desafiantes en la praxis que involucra el aprendizaje y la enseñanza. Así, este artículo presenta algunas reflexiones sobre distintas concepciones de la alfabetización que, a su vez, nos permitirán establecer una especie de rueda dialógica con algunos autores y sus supuestos teóricos. Buscamos, por tanto, crear un movimiento donde los diversos significados del término alfabetización se confronten y completen, 
generando una perspectiva ampliada para este proceso múltiple y singular. Metodológicamente, se buscó la literatura sobre los procesos de alfabetización, especialmente los estudios de Magda Soares y también las intersecciones de algunas concepciones teóricas con la praxis de alfabetización de Paulo Freire. Como resultado, esperamos que los educadores puedan hacer uso de los múltiples significados (polisemia) que cubre el término alfabetización.

Palabras clave: alfabetización; dialogía; letramiento; polisemia.

\section{INTRODUÇÃO}

Uma publicação voltada para celebração do centenário de Paulo Freire nos traz alento num tempo em que a memória de Freire vem sendo tão atacada, bem como suas brilhantes colaborações para construção de uma educação humanizada e humanizadora vem sendo tão desmerecidas. Num ano em que o fazer educativo precisou se ajustar para garantir o isolamento social, a oportunidade de colaborar com reflexões sobre práticas e discussões polêmicas nos renova o oxigênio. Como dizia Freire, é uma forma de esperançar.

Os educadores brasileiros, diante da grave Pandemia do Covid-19, se viram obrigados a se reinventarem. Foi preciso reorganizar as ações, partilhar em redes virtuais experiências, sobretudo, reacender as lutas e resistências em defesas dos sujeitos que, possivelmente, seriam mais uma vez excluídos. Agora a excludência bateu à porta por meio das atividades remotas que não são acessíveis para grande parcela da população.

Ao olharmos para os percalços e para as conquistas da educação brasileira é difícil não nos depararmos com as contribuições de Paulo Freire, sobretudo, os ensinamentos que nos orientam a olhar, compreender e agir em situações que envolvem a diversidade de sujeitos, seus saberes, suas culturas e os lugares concretos ondem produzem sua própria existência. No entanto, sabemos que o modo com que Freire vivenciou as realidades e a forma com que orientou as ações dos educadores vem sofrendo ataques inconsequentes nos últimos anos. Portanto, é providencial um dossiê para celebrar o centenário de nascimento do patrono da educação brasileira.

Como educadores fomos tocados pela proposta de um dossiê que se propõe estimular a reflexão sobre as múltiplas formas de abordagem das realidades plurais e sobre metodologias dialógicas voltadas para os sujeitos imersos nas mais diversas formas de opressão. Consideramos um privilégio poder celebrar a memória e a grandiosidade de Freire através de uma produção como esta. Para organizar nossas reflexões, nosso objetivo é criar um movimento onde os vários sentidos do termo alfabetização se confrontam e se completa, gerando uma perspectiva ampliada para esse processo múltiplo e singular.

O legado freireano que faz parte da nossa constituição humana e educativa delineia nossa ação docente, de modo que, ao olharmos para uma problemática não é possível apenas nos inserirmos passivamente. Conduzidos pela perspectiva freireana, nossa inserção se reveste de um caráter participativo, mas, sobretudo, intencionando contribuir para superação do problema posto.

Essa forma de nos colocarmos no mundo direciona nossos olhares quando buscamos problematizar algumas questões acerca da alfabetização. O que nos preocupa é que a cada dia mais jovens se tornam potenciais integrantes de classes de alfabetização de jovens e adultos. Buscando contribuir para superação dessa lamentável situação apresentamos algumas reflexões que partem das seguintes problematizações: em que se sustentam as ações pedagógicas e justificativas legais de um processo alfabetizador que prioriza apenas a aquisição da leitura, da escrita e de simples cálculos. Consequentemente, ainda nos perguntamos: Que alfabetização é essa? Quais os seus alcances? Que elementos a constituem? Qual o papel da dialogia no processo alfabetizador?

Essa e tantas outras questões, bem como a coragem de adentrar numa temática tão polêmica nos debates acadêmicos, e ainda, a possibilidade de oferecer aos leitores algumas reflexões 
na perspectiva freireana, tem como incentivo palavras do mestre que nos impulsionam para deixarmos nossas contribuições no mundo: "não haveria criatividade [e pesquisa] sem a curiosidade que nos move e que nos põe pacientemente impacientes diante do mundo que não fizemos, acrescentando a ele algo que fazemos" (FREIRE, 1996, p. 35).

\section{MULTIPLICIDADE DO PROCESSO ALFABETIZADOR}

Remontando o caminhar construtivo sobre o entendimento do que chamamos alfabetização, uma outra nomenclatura surgiu nos debates educacionais que, por vezes, redimensionava a amplitude com que Freire sempre discorreu e atuou com os processos alfabetizadores. Trata-se da ampliação de carga semântica que, delimita o sentido de alfabetização e tenta explicar os processos pedagógicos, cognitivos e sociais a partir de outros vocábulos. Falamos especificamente do uso de vocábulos como: alfabetismo e letramento.

As tentativas de delimitar a significação de alfabetização ganham impulso no início da década 90, quando nas discussões acadêmicas aparece o termo alfabetismo usado para designar concepções voltadas ao uso da leitura e da escrita em determinado contexto social, ou como formula Magda Soares (2003, p. 45), alfabetismo seria um "conjunto de práticas governadas pela concepção de o quê, como, quando e por quê ler e escrever".

$\mathrm{Na}$ pretensão de ampliar a carga semântica do vocábulo designado, bem como explicar o desenvolvimento da leitura e da escrita surge, advinda do termo inglês literacy, a palavra letramento. Uma grande e congestionada avenida surge a partir das formulações apresentadas acerca da concepção de letramento. Dentre autoras e autores que apresentam tais formulações destacam-se Magda Soares (1998; 2002; 2003), Ângela Kleiman (1995; 1998), Vera Masagão (2004), Leda Tfouni (1995) e Marcos Bagno (2002).

Segundo Soares (2002), as tentativas de conceitualização possibilitam a emersão de duas vertentes que buscam explicar a concepção, sobretudo de letramento. De um lado Kleiman (1995, p. 21) concebe letramento como "as práticas sociais de leitura e escrita e os eventos em que essas práticas são postas em ação, bem como as consequências delas sobre a sociedade".

Encontramos também outra formulação de letramento que se confronta com uma ideia reducionista de alfabetização. Nessa direção Leda Tfouni (1995, p. 20) concebe letramento como "as consequências sociais e históricas da introdução da escrita em uma sociedade", afirmando um caráter social para o letramento que, segundo a autora, se contrapõe ao caráter individual que tem a alfabetização.

Essa separação entre alfabetização e letramento dá à primeira uma dimensão limitada em que atribui ao ato de alfabetizar apenas uma decodificação da língua oral em língua escrita e, viceversa, decodificação da língua escrita em oral. Circunscrevendo o rico processo de alfabetização em mero ato de representação de fonemas em grafemas e de grafemas em fonemas.

Atentando para a trajetória de produção de Soares, é possível perceber que a autora em determinados escritos subscreve essa visão ao dizer que: “tem-se tentado, ultimamente, atribuir um significado demasiado abrangente à alfabetização, considerando-a um processo permanente... [...] etimologicamente, o termo alfabetização não ultrapassa o significado de 'levar à aquisição do alfabeto"' (SOARES, 2003, p. 37).

Após passados anos das primeiras definições de letramento ainda se tenta restringir o significado da alfabetização. Enquanto a reduz a simples aquisição da leitura e da escrita, busca-se ampliar a significação de letramento. Nesse sentido, é que continuamos a análise de algumas proposições de Soares (2004b). Ainda fazendo a cisão entre os conceitos, diz que: 
É necessário reconhecer que alfabetização - entendida como a aquisição do sistema convencional escrita - distingue-se de letramento - entendido como o desenvolvimento de comportamentos e habilidades de uso competente da leitura e da escrita em práticas sociais; distingue-se tanto em relação aos objetivos de conhecimento quanto em relação aos processos cognitivos e linguísticos de aprendizagem e, portanto, também de ensino desse diferentes objetos - isso explica porque é conveniente a distinção entre os dois processos. (SOARES, 2004b, p. 20)

Em outra produção, a autora reconhece que os dois conceitos frequentemente são confundidos e sobrepostos. Diz ser necessário distingui-los, mas também aproximá-los, pois, no campo educacional corre-se o risco de ameaçar a especificidade da alfabetização (2004a, p. 90). Segue afirmando que:

[...] embora correndo o risco de excessiva simplificação, pode-se dizer que a inserção no mundo da escrita se dá por meio da aquisição de uma tecnologia - a isso se chama alfabetização, e por meio do desenvolvimento de competências (habilidades, conhecimentos, atitudes) de uso efetivo dessa tecnologia em práticas sociais que envolvem a língua escrita - a isso se chama letramento. (SOARES, 2004a, p. 90)

Segue ainda buscando a associação entre os dois conceitos:

Embora distintos, alfabetização e letramento são interdependentes e indissociáveis: a alfabetização só tem sentido quando desenvolvida no contexto de práticas sociais de leitura e escrita e por meio dessas práticas, ou seja: em um contexto de letramento; este, por sua vez, só pode desenvolver-se na dependência por meio da aprendizagem do sistema de escrita. (SOARES, 2004a, p. 90)

Em outros momentos, a autora faz críticas a visão "liberal" que reduz pragmaticamente o conceito de leitura e de escrita, na tentativa de se alcançar uma perspectiva "radical" para esses conceitos:

Sob essa perspectiva de uma visão progressiva, "liberal" do conceito de domínio da leitura e da escrita, as habilidades de ler e escrever não podem ser dissociadas de seus usos, não podem ser desligadas das formas empíricas que efetivamente assumem na vida social; [...] as habilidades de leitura e de escritas não são vistas como "neutras", mas são vistas como um conjunto de práticas socialmente construídas envolvendo o ler e o escrever. (SOARES, 1994, p. 144)

Buscando amenizar esse pragmatismo, Soares (2002) formula outro conceito de letramento. Essa formulação tem o objetivo de ir além da dimensão prática e técnica do conceito. Introduz assim o sujeito-escritor-leitor nos eventos de letramento. A autora afirma que letramento é:

[...] não as próprias práticas de leitura e escrita, e/ou os eventos relacionados com o uso e função dessas práticas ou ainda o impacto ou as consequências da escrita sobre a sociedade, mas, além de tudo isso, o estado ou a condição de quem exerce as práticas sociais de leitura e de escrita, de quem participa de eventos em que a escrita é parte integrante entre pessoas e do processo de interpretação dessa interação - os eventos de letramento. (SOARES, 1994, p. 145) 
DOI: $10.12957 /$ teias.2021.62397

Consideramos que as tentativas de trabalhar os conceitos de alfabetização e letramento de forma indissociáveis e interdependentes, de fazer críticas a essa visão liberal/pragmática e de integrar o sujeito leitor às práticas de ler e escrever; não diminuem o fosso entre esses conceitos. Não obstante, abre-se a possibilidade para uma visão de alfabetização em sentido lato.

Esse movimento indissociável e interdependente que perpassa os termos alfabetização e letramento afastam, mesmo que no campo teórico, a sobreposição de um conceito em relação ao outro e cria uma tentativa de intersecção entre os conceitos.

Mas, nossa opção nos conduz a assumirmos e trabalharmos com a amplitude do termo alfabetização. Essa não é uma opção por uma simples nomenclatura, mas, sobretudo, por considerarmos a alfabetização imbricada/imbricante de/por uma visão de totalidade.

A alfabetização que concebemos/vivemos/exercemos não se reduz a simples aquisição da leitura e da escrita, mas como diz Freire (1987a):

[...] alfabetização implica não em uma memorização mecânica das sentenças, das palavras das silabas, desvinculadas de um universo existencial - coisas mortas ou semimortas - mas uma atitude de criação e recriação. Implica uma auto formação da qual pode resultar uma postura atuante sobre o seu contexto. (FREIRE, 1987a, p. 72 - grifos nossos)

Alfabetização, como esse ato criador e recriador de que fala Freire, que proporciona ao alfabetizando pensar/viver/agir no seu contexto existencial, abrindo a possibilidade para transformação de si, do outro e do conjunto da sociedade. A alfabetização de que fala Freire não pode ser reduzida/dissociada do contexto social.

Alfabetização nessa perspectiva não pode ser vista como algo exterior ao indivíduo. Ela precisa valorizar a dialogicidade transformadora que perpassa a ação alfabetizadora e que transforma os atores desse processo. Assim, ressaltamos a perspectiva de alfabetização em Freire:

É a consequência de uma reflexão que o homem começa a fazer sobre sua própria capacidade de refletir. [...] Reflexão sobre a própria alfabetização, que deixa de ser algo externo ao homem, para ser dele mesmo. Para sair de dentro de si, em relação com o mundo, como uma criação. Só assim nos parece válido o trabalho da alfabetização, em que a palavra seja compreendida pelo homem na sua significação: como uma força de transformação do mundo. (FREIRE, 1975, p. 117 - grifos nossos)

Concebida/vivida/exercida dessa forma, a alfabetização, como um dos organismos superestruturais na esfera da sociedade civil, poderá contribuir para uma transformação do homem e da sociedade.

Alfabetização que abraça e se sustenta em iniciativas pedagógicas que têm como eixo estratégias de ações educativas voltadas para superação/reversão das desigualdades, sejam elas sociais, cognitivas e/ou afetivas. Iniciativas pedagógicas, marcadas por uma intencionalidade, em que um sujeito está se constituindo de forma relacional (eu, o outro e o contexto). Dessa forma, no processo alfabetizador "Constitui-se pelo outro, constituindo-se a si mesmo e simultaneamente constituindo o outro. É constituído pela sociedade, ao mesmo tempo em que constitui esta mesma sociedade (o contexto histórico-cultural) em que está inserido" (REIS, 2011, p. 53). Intencionalidade pedagógica/política/social/educativa que constrói cotidianamente por meio da dialogia a possibilidade do sujeito se constituir nos limites e possibilidades das relações sociais de classe. 
Tendo a intencionalidade de exercitar um processo alfabetizador voltado para a superação das desigualdades sociais, cognitivas e/ou afetivas o aspecto transformador, perpassa e se torna inerente à vida das (os) educandas (os), da (o) educadora/educador, do pesquisador e demais participantes do processo educativo. Intencionalidade política-epistemológica que o educador freireano, Renato Hilário dos Reis (2011) formula como sendo:

Ação alfabetizadora que intenciona não só uma apropriação da leitura, escrita e
do cálculo em sentido estrito, mas, também apropriação intrínseca a um processo
de aprendizagem e desenvolvimento, situado na contradição das relações sociais
vividas e enfrentadas pelos vários sujeitos participantes do processo
alfabetizador. Nesse processo, se constituindo praxicamente a
autotransformação de cada sujeito. Sua transformação na relação com o outro ou
outros. E toda essa transformação do sujeito e de sujeitos, sendo constituída e
constituindo o contexto histórico cultural em que estão inseridos. (REIS, 2011,
p. 66)

Ao pensar e conceber essas transformações como parte constitutiva/constituinte do processo alfabetizador torna-se necessário assumirmos que elas se dão no contexto de um processo de significação que ocorre com cada sujeito na relação consigo mesmo, nas relações uns com os outros e com o contexto histórico-cultural em que estão inseridos.

Ao apresentarmos nosso entendimento acerca da significação, por sua ver relacionada com a perspectiva freireana de alfabetização, optamos pela reafirmação do que Vygotsky repetidas vezes disse em suas obras: "nós nos tornamos nós mesmos através dos outros" (VYGOTSKY, 1989, p. 27). Reafirmado isto, precisamos dizer ainda que esse outro não pode ser visto como um simples mediador instrumental no desenvolvimento histórico-cultural de um determinado sujeito.

Ao explicar o desenvolvimento cultural a partir do processo de significação, Angel Pino (2000), retoma formulações de Vygotsky e diz que este considera que o desenvolvimento históricocultural passa por três momentos: o desenvolvimento em si, para os outros e para si:

Vygotsky marca em suas obras esse movimento em que o indivíduo com o outro constrói sua própria história. É importante lembrar que nesses três momentos não existe uma açãoconstitutiva estabelecida a priori. As ações ocorrem simultaneamente possibilitando ao indivíduo se constituir, constituir ao outro e colabora para a constituição da sociedade através das relações sociais estabelecidas.

Com um exemplo aparentemente simples, Vygotsky demonstra o caminho da inserção da criança na história cultural dos homens. Em síntese diz que, é pela significação que o outro atribui às expressões da vida natural ou biológica da criança, como por exemplo o movimento de apontar, é que estas adquirem significação para ela. Assim, afirma que "a criança é a última a reconhecer seu gesto, ou seja, só capta a significação do seu ato através do outro” (PINO, 2000, p. 65).

Esse caminhar histórico-cultural e os processos de significação levam Angel Pino (1996) a construir, a partir das formulações de Vygotsky, asserções que marcam o papel das relações sociais na constituição do indivíduo no plano pessoal. Afirma que: "o modo pela qual a criança (cada ser humano) se torna um ser cultural é a sua inserção, com a mediação do outro, no circuito da significação ou da semiose humana". (PINO, 1996, p. 27)

O papel das relações sociais na constituição histórico-cultural do homem remete a várias questões que precisam ser discutidas para que sirvam de elementos de análise na presente reflexão. Questões como conversão, internalização, significação e semiose que, por sua vez são circundadas por polêmicas, tornam-se necessários para compreensão do processo de constituição e, consequentemente para o sentido amplo de alfabetização que estamos a defender. 
Para que se compreenda o alcance do conceito de internalização, na perspectiva de Vygotsky, fazemos uma separação didática de alguns termos/conceitos que a compõe na tentativa de explicá-la, bem como superar algumas polêmicas.

Partindo do estudo do termo conversão, torna-se possível perceber - em primeira análise que ele se refere à transformação das relações sociais em funções psicológicas, num movimento simultâneo. Aprofundando a análise, percebe-se que a conversão remete à mudança de uma condição "X" para uma condição "Y". Mudança que conserva algo essencial na relação constitutiva/constituinte, tornando assim o processo de conversão um processo reversível. Reversibilidade que, por sua vez, é função mediadora da significação, pois o que é social se converte em pessoal e o que é pessoal se converte em social, garantindo assim a coerência e a simultaneidade entre os mundos públicos e privados da pessoa.

Conversão, reversibilidade, esfera pública e privada são alguns dos elementos que Pino (2000) utiliza para explicar o que ocorre nos processos de significação. O autor apresenta dois sentidos para o termo conversão na tentativa de esclarecer a maneira como se dá o processo de transformação ou internalização.

Refiro-me ao uso comum desse termo para designar a mudança por que podem
passar as pessoas no campo das ideias (políticas, sociais ou religiosas) num
determinado momento de sua vida. Mudança que pressupõe a emergência de algo
novo e diferente a partir de algo que, na sua essência, continua o mesmo (a água
não deixa de ser água por passar do estado líquido ao estado gasoso ou sólido e
a pessoa não deixa de ser ela por mudar de religião ou ideologia, mas, em ambos
os casos nem a água nem a pessoa são as mesmas). A conversão implica uma
diferença de uma semelhança. (PINO, 2000, p. 68)

Com as pistas fornecidas, torna-se possível dizer que a pessoa ao passar pelo processo de conversão transforma - simultânea e dialeticamente - as relações sociais em relações intrapessoais. Nesse processo o elemento que continua o mesmo é a significação.

Para Angel Pino (2000), a significação precisa ser vista como um mecanismo que através da palavra do outro possibilita a conversão das relações sociais em funções superiores do indivíduo. A conversão que torna possível esse movimento intrapessoal se dá através da internalização, mas o que é internalizado é a significação das coisas e não as coisas em si mesmas.

Para esclarecer melhor essa internalização Pino (2000) diz que:

[...] o que é internalizado das relações sociais não são as relações materiais, mas a significação que elas têm para as pessoas. Significação que emerge na própria relação. Dizer que o que é internalizado é a significação dessas relações equivale dizer que o que é internalizado é a significação que o outro da relação tem para o eu; o que, no movimento dialético da relação, da ao eu as coordenadas para saber que ele é que posição ocupa é o que se espera dele. Dito de outra forma, é pelo outro que o eu se constitui em um ser social com sua subjetividade - o que é coerente com o modelo dos três estágios. (PINO, 2000, p. 68)

O processo de conversão não é automático, ao contrário, requer um sujeito interpretante que gera, indefinidamente, outro (s) interpretante (s), outro (s) signo (s) e outro (s) contexto (s) sociocultural. Asserção que rompe com a visão dicotômica e simplista que imprime às construções de Vygotsky um inexistente erro epistemológico: a destituição do sujeito em detrimento de um determinismo do meio social-cultural. Entendido esse processo pode se acalmar os que criticam Vygotsky em função da falsa supremacia das questões interpessoais (externo) em detrimento das intrapessoais (interno). Ou seja, se faz necessário demarcar que existe uma simultaneidade dialética 
para fazer frente à visão mecanicista que considera que a dinâmica social (interpessoal) predomina sobre a dimensão individual (intrapessoal).

Consideramos assim que, a sociedade onde ocorrem as relações interpessoais são, como diz Marx, "uma rica totalidade de determinações e relações diversas" (MARX, 1982, p.14), ou seja, a sociedade é algo concreto e, por sua vez, "o concreto é concreto porque é a síntese de muitas determinações, isto é, unidade do diverso" (MARX, 1982, p.14). Percebendo esse movimento de simultaneidade/síntese/unidade, rechaça-se a ideia de haver primeiro uma relação interpessoal para depois haver um processo intrapessoal por meio da internalização. Esses processos são simultâneos.

Dessa forma, olhar para a questão dos processos externos e internos, pressupõe analisar na simultaneidade dialética a trama das relações sociais que envolve não só os aspectos individuais, mas, de forma relacional e simultânea, os aspectos sociais. Nessa perspectiva, Reis (2011) contribui para compreensão dessa simultaneidade ao dizer que: "o desenvolvimento da individualidade humana se dá, pois, em um processo histórico, segundo condições específicas de um determinado momento histórico das forças produtivas e das relações sociais características destas. Esse desenvolvimento tem ao mesmo tempo um caráter singular: específico e geral: de totalidade" (REIS, 2011, p. 97).

Sendo esses processos simultâneos, envolto por uma "reciprocidade que é precisamente o processo dialético" (GRAMSCI, 1981. p. 53), reafirmamos que o sujeito age sobre os objetos/conhecimentos através de uma atividade mediada socialmente, pelo outro e pelos signos, tornando-se assim um processo de aprendizagem mútua. A percepção consciente de estar no mundo e agir para transformá-lo nos leva a buscar aproximação com outra importante formulação de Paulo Freire (1996):

É neste sentido que, para mulheres e homens, estar no mundo necessariamente significa estar com o mundo e com os outros. Estar no mundo sem fazer história, sem por ela ser feito, sem fazer cultura, sem "tratar" sua própria presença no mundo, sem sonhar, sem musicar, sem cuidar da terra das águas, sem usar as mãos, sem esculpir, sem filosofar, sem pontos de vista sobre o mundo, sem fazer ciência, ou teologia, sem assombro em face do mistério, sem aprender, sem ensinar, sem ideias de formação, sem politizar não é possível. (FREIRE, 1996, p. 64)

A respeito das transformações possíveis e necessárias que, por sua vez, se faz pela mediação por signos, Reis (2011) contribui ao demonstrar que a realidade é o complexo de múltiplas determinações e que a mediação pode ser percebida como uma categoria básica da dialética:

Nessas múltiplas determinações se inscrevem mediações (uma das categorias centrais da dialética). No desenvolvimento, na constituição mediada do ser humano podem ocorrer saltos qualitativos, transformações inesperadas, avanços e recuos imprevistos, dependendo das condições objetivas de cada tempo e época e a iniciativa transformativa política dos homens no confronto de suas origens e posições de classe. (REIS, 2011, p.101)

Processo esse em que a mediação semiótica (particularmente a linguagem) torna-se elemento fundamental. Essa mediação, como nos diz Roseli Fontana, "envolve as ações do sujeito, as estratégias e conhecimentos por eles já dominados, as ações, estratégias e conhecimentos do (s) outro (s) e as condições sociais reais de produção das interações" (FONTANA, 2000, p. 12). Nesse movimento, o sujeito controla suas ações, seus papéis e funções sociais, dirigindo assim o próprio comportamento. Para Vygotsky (1989), essa autorregulação é essencial para o desenvolvimento, 
pois possibilita que as funções psicológicas elementares/primárias, em um movimento "em sendo", transformem-se em função mediada/consciente e deliberada, ou seja, funções psicológicas superiores.

Percebemos a necessidade de construir uma ação educativa em que os sujeitos envolvidos possam ser articuladores, planejadores e avaliadores dessa ação. Essa ação intermediada pela linguagem/dialogia poderá proporcionar que os sujeitos (na simultaneidade) pensem suas ações, suas estratégias e organizem os conhecimentos já dominados, por si próprios e pelos demais envolvidos no processo alfabetizador.

Considerando o poder que a linguagem tem nessa ação educativa, cabe destacar que, em meio à diversidade da linguagem, encontra-se a palavra que se apresenta estreitamente ligada ao pensamento. A fim de reforçar essa premissa Reis (2011) diz que:

A palavra e o pensamento constituem a chave para a compreensão da natureza
da consciência humana. A palavra não só desempenha um papel central no
desenvolvimento do pensamento, mas também na evolução da história da
consciência como um todo, sendo um microcosmo dessa própria consciência. A
relação entre pensamento e palavra é um processo vivo: o pensamento nasce
através das palavras. Uma palavra desprovida de pensamento é uma coisa morta
e um pensamento não expresso por palavras é uma coisa morta. A relação entre
pensamento e palavra não é algo constante, acabado, concluído, surge e se
transforma ao longo do desenvolvimento humano. (REIS, 2011, p. 93)

Importante destacarmos que quando falamos desse movimento transformador estamos falando necessariamente do legado de Freire. Se a nossa constituição se dá ao longo do desenvolvimento humano, mediada pela palavra e pelo pensamento, não cabe a (ao) educadora (educador) um papel preponderante no ato pedagógico. Esta (e) não determinará a aprendizagem das (dos) educandas (os), pois a aprendizagem se desenvolverá permeada por uma dialogia que é dialética e ao mesmo tempo pedagógica que possibilite a construção de novos saberes e a superação das dificuldades da não-aprendizagem.

Esse processo dialógico é presente em diversos ensinamentos freireanos, dentre eles destacamos a conhecida frase, na qual se assenta muitas elaborações conceituais e metodológicas: "ninguém educa ninguém, como tampouco ninguém se educa a si mesmo: os homens se educam em comunhão, mediatizados pelo mundo" (FREIRE, 1987, p. 79). Podemos dizer ainda que, quando buscamos ampliar nossos olhares para a alfabetização, relacionando com outros construtos teóricos, estamos defendendo um processo através do qual fazemos história, fazendo-nos por/com ela, nos colocando em um constante movimento de busca, pois "a consciência do mundo e a consciência de si como ser inacabado necessariamente inscrevem o ser consciente de sua inconclusão num permanente movimento de busca" (FREIRE, 1996, p. 64).

Como o propósito de fortalecer uma perspectiva ampliada de alfabetização seguimos estabelecendo intersecções das elaborações de Freire acerca da dialogia com outros construtos teóricos. Freire (1980b), ao apresentar uma afirmação sobre o que é educação destaca a dialogicidade como princípio basilar da mesma, pois afirma que: "a educação é comunicação, é diálogo, na medida em que não é a transferência de saber, mas um encontro de sujeitos interlocutores que buscam a significação dos significados" (FREIRE, 1980b, p.69).

O diálogo para Freire (1987a) é o que permite que os seres humanos, como seres conscientes e comunicativos, estabeleçam suas relações com a intenção de conhecer e refletir sobre sua realidade. Portanto, como diz o autor, "o diálogo deve ser entendido como algo que faz parte 
da própria natureza histórica dos seres humanos. É parte de nosso progresso histórico do caminho para nos tornarmos seres humanos" (FREIRE, 1986, p.122-3).

Olhando o indivíduo como um ser histórico e cultural, percebe-se que a historicidade desses se constitui/constrói no movimento de afirmação/negação de que fazem parte as relações sociais. Assim, olhar para essas relações é olhar para todo o passado da nossa espécie. Ou seja, "o diálogo pertence à natureza do ser humano, enquanto ser de comunicação. O diálogo sela o ato de aprender, que nunca é individual, embora tenha uma dimensão individual” (FREIRE, 1986, p.14).

A dimensão social da dialogia freireana pode ser percebida quando o autor destaca a intersubjetividade que a constitui. A relação recíproca é muito evidente quando nos diz que: "o diálogo tem significação precisamente porque os sujeitos dialógicos não apenas conservam sua identidade, mas a defendem e assim crescem um com o outro. O diálogo, por isso mesmo, não nivela, não reduz um ao outro. Nem é favor que um faz ao outro" (FREIRE, 1993a, p.118).

Essa intersubjetividade também nos aponta que o diálogo freireano é solidário e amoroso, pois, nas suas palavras "o diálogo é o encontro amoroso dos homens [e mulheres] que, mediatizados pelo mundo, o pronunciam, isto é, o transformam, e transformando-o, o humanizam para a humanização de todos" (FREIRE, 1980b, p. 43).

Nessa relação física entre pessoas se presentifica a elaboração/reelaboração dialógicadialética de que fala Bakhtin (1997a), onde "palavras alheias", tornam-se "palavras próprias alheias", transformando-se processualmente em palavras próprias. Esse percurso da palavra (na dimensão verbal, não-verbal e escrita), expresso pelo processo de constituição mútua, poderá possibilitar um processo alfabetizador diferenciado.

$\mathrm{Na}$ mediação do/pelo outro, revestida de gestos, atos e palavras/pensamentos (signos) o ser humano vai integrando-se, ativamente, às formas de atividade consolidadas de sua cultura num processo em que pensamento e linguagem articulam-se dinamicamente. Proporcionando, por exemplo, a superação das dificuldades de aprendizagem através não apenas da prática alfabetizadora mecânica preocupada com o ler e o escrever, mas, quando esse ser humano se integra com o outro e com mundo que o cerca, acaba lendo muito além das letras.

Portanto, na busca pela superação de uma prática alfabetizadora mecanizada se faz necessário ir além da "pedagogia da resposta". Para Freire (1985 e 1986), existem educadores que praticam uma "castração da curiosidade, pois já traz a resposta sem lhe terem perguntado nada" (1985, p. 46), bem como concebe o ato de conhecer como uma "mera transferência do conhecimento existente" (1986, p. 18). Para fazer frente a "pedagogia da resposta", Freire (1987a) demarca que o eu antidialógico é responsável por subsidiar a educação bancária; enquanto o eu dialógico sustenta a educação libertadora. Sobre essa dualidade diz o autor que:

$\mathrm{O}$ eu antidialógico, dominador, transforma o tu dominado, conquistado num mero "isto". O eu dialógico, pelo contrário, sabe que exatamente o tu que o constitui. Sabe, também, que, constituído por um tu - um não-eu - esse tu que o constitui se constitui, por sua vez, como eu, ao ter no seu eu um tu. Desta forma, o eu e o tu passam a ser, na dialética destas relações constitutivas, dois tu que se fazem dois eu. (FREIRE, 1987a, p. 196).

Num processo alfabetizador ampliado, o fortalecimento do eu dialógico poderá acontecer por meio de uma exercitação individual/coletiva (que pressupõe uma ação retro alimentadora e simultânea entre eu, o outro e o conjunto da sociedade) que, por sua vez se constitui através dos instrumentos. Estes são entendidos, segundo Vygotsky (2000), como o elo entre o homem e o ambiente. Para ele, são os instrumentos que diferenciam os homens dos animais, pois ampliam e modificam sua forma de ação sobre um determinado objeto. $\mathrm{Na}$ abordagem histórico-cultural, essa 
DOI: $10.12957 /$ teias.2021.62397

relação entre homem e objeto é mediada por produtos culturais humanos como o próprio instrumento e os signos, bem como pelo outro.

Já o signo para Vygotsky é visto como um “instrumento psicológico”. Nesse sentido, tudo o que é utilizado pelo homem para representar, evocar ou tornar presente o que está ausente constitui-se em um signo: a palavra, o sentir, o pensar, os desenhos etc.

Podemos perceber que essas elaborações podem se aproximar da perspectiva dialógica defendida por Freire nas suas ações alfabetizadoras, pois, a dialogicidade se expressa numa totalidade composta pelas propriedades do pensamento discursivo (como diz Vygotsky) ou do todo real da comunicação (como diz Bakhtin).

Proposições vygotskyanas que se aproximam das de Bakhtin na mediada em que ambos concebem que a palavra (signo por excelência) não é constante e imutável, ou seja, ela não é somente a "associação estabelecida pela reiterada coincidência, na consciência, da impressão deixada pela palavra e da impressão deixada pelo objeto designado por essa palavra" (VYGOTSKY, 2000, p. 399). Ou ainda, palavra morta, apenas como parte de uma realidade, quando não se considera que a mesma tem o poder de refletir e refratar uma outra realidade, tornando-se palavra viva que, segundo Bakhtin (1997b), tem o poder de apreender, distorcer ou transformar uma realidade.

O diálogo, a palavra que transforma uma realidade, precisam ser considerados no processo alfabetizador como a ação que através da qual "o ser humano conhece e transforma o mundo e sofre os efeitos de sua própria transformação" (FREIRE, 1980b, p. 52). Nessa perspectiva, o diálogo não aprisiona o ser humano e sim o liberta. A conquista implícita nele é a do mundo para a libertação dos seres humanos e não de um pelo outro (FREIRE, 1987a). Portanto, como diz Freire (1980a, p.69), "a dialogação implica a responsabilidade social e política do ser humano", desse modo, o ser humano poderá "não fenecer no isolamento".

Consideramos que os conceitos levantados são fundamentais para se construir essa ação alfabetizadora que não se prende aos princípios do alfabetismo e do letramento. Reforçamos ainda que, para construção dessa ação alfabetizadora o diálogo tem um papel fundamental. Acreditamos que o diálogo se constituirá realmente num processo semiótico à medida que se configurar como uma alternância entre sujeitos falantes, condicionando os signos advindos da relação dialógica, tanto em nível da organização social dos falantes, quanto das condições subjetivas/pessoais destes e, ainda, das condições em que ocorrem as interações entre os sujeitos. Esse é um dos tantos ensinamentos que Freire nos presenteou quando fala que: "gosto de ser gente porque a História em que me faço com os outros e de cuja feitura tomo parte é um tempo de possibilidades e não de determinismos" (FREIRE, 1996, p. 58).

\section{CONCLUSÃO}

Essas questões emergem por considerarmos que a alfabetização que acreditamos, vivemos e exercemos tem esse poder transformador que permeia e, é permeado, pelas relações dialógicasdialética-pedagógicas-humanas.

Nesse sentido, não é nosso objetivo aprofundar questões de afirmação ou negação conceitual que cercam os termos letramento, alfabetismo e alfabetização. Ou mesmo, nos aprofundarmos nas construções acerca do pensamento e da linguagem. Mas, a presente reflexão se apresentou para nós não apenas como um desafio. Encaramos a tarefa reflexiva mais como uma possibilidade de evidenciar a universalização do pensamento freireano que, quando colocado lado a lado com outras construções educativas que primam pela humanização, promovem uma interseção que permitem a construção de novos horizontes para a ação alfabetizadora. 
DOI: $10.12957 /$ teias.2021.62397

Por isso, independentemente de ser a alfabetização um processo que perdure por toda a vida (característica que alguns críticos dão a ela), acreditamos que o processo alfabetizador que marca nossa caminhada constitutiva, respeita/considerada a singularidade/unidade e a multiplicidade de cada educanda (o). Não se reduzindo a uma esfera mecânica na qual vincula o processo alfabetizador às habilidades de codificação (ou representação escrita de fonemas em grafemas) e/ou decodificação (ou representação oral de grafemas em fonemas).

Alfabetização numa perspectiva contributiva/transformadora da sociedade de classe, onde "a leitura do mundo precede sempre a leitura da palavra escrita e a leitura desta implica sempre na leitura daquele" (FREIRE, 1987b. p. 22). Assim, concluímos afirmando que esta reflexão acabou por se tornar um processo de auto constituição, pois, pensar a alfabetização numa perspectiva ampliada permitiu suscitar nossa transformação enquanto educadores, mas também podem nos ajudar a contribuir para a transformação das (os) educandas (os), e das relações sociais em nós todos (as) nos inserimos.

\section{REFERÊNCIAS}

BAKHTIN, Mikhail. Estética da Criação Verbal. São Paulo: Martins Fontes, 1997a.

FONTANA, Roseli A. Cação. Mediação Pedagógica em sala de aula. $3^{\mathrm{a}}$ ed. Campinas, SP: Autores Associados, 2000. - (Coleção educação contemporânea).

FREIRE, Paulo; SHÖR, I. Medo e ousadia: o cotidiano do professor. Rio de Janeiro: Paz e Terra, 1986.

FREIRE, Paulo; FAUNDEZ, A. Por uma Pedagogia da Pergunta. Rio de Janeiro: Paz e Terra, 1985.

FREIRE, Paulo. Pedagogia do oprimido. 13 ed. Rio de Janeiro: Paz e Terra, 1987a.

FREIRE, Paulo. A importancia do ato de ler: em três artigos que se completam. 18 ed. São Paulo: Cortez, 1987b.

FREIRE, Paulo. Educação como prática da liberdade. 11 ed. Rio de Janeiro: Paz e Terra, 1980a.

FREIRE, Paulo. Extensão ou comunicação? 5 ed. Rio de Janeiro: Paz e Terra, $1980 \mathrm{~b}$.

FREIRE, Paulo. Educação como Prática de Liberdade. $5^{\mathrm{a}}$ ed. Rio de Janeiro, Paz e Terra: 1975.

FREIRE, Paulo. Pedagogia da Autonomia: saberes necessários à prática educativa. 25 ed. São Paulo: Paz e Terra, 1996.

FREIRE, Paulo. Criando métodos de pesquisa alternativa: aprendendo a fazê-la melhor através da ação. In: BRANDÃO, Carlos Rodrigues (org.) Pesquisa participante. $3^{\mathrm{a}}$ ed. SP: Ed. Brasiliense, 1983.

GRAMSCI, Antonio. Concep̣cão Dialética da História. $3^{\mathrm{a}}$ Ed. Rio de Janeiro: Civilização Brasileira, 1981.

KLEIMAN, Ângela B. (org.). Os significados do letramento: uma nova perspectiva sobre a prática social e escrita. Campinas, SP: Mercado da Letras, 1995.

MARX, Karl. Para a Crítica da Economia Política: Salário, Preço e lucro, o rendimento e suas Fontes. Tradução de Edgar Malagod. São Paulo: Abril Cultural, 1982.

PINO, Angel. Constituição e Modos de Significação do Sujeito no Contexto da Pré-escola. In.: PEDROSA, Maria Isabel (org.). Investigação da criança em interação social. Coletânea da ANPEPP, vol. IV. Recife: Editora Universitária da UFPe, 1996.

PEDROSA, Maria Isabel (org.). O social e o cultural na obra de Vygotsky. In.: Educação e Sociedade: Revista quadrienal de Ciências da Educação: Centro de Estudos Educação e Sociedade (CEDES). $2^{\mathrm{a}}$ ed. $\mathrm{N}^{\mathrm{o}}$ 71. Campinas, SP: 2000. 
DOI: $10.12957 /$ teias.2021.62397

REIS, Renato Hilário dos. A constituição do ser bumano: amor, poder, saber na educação/alfabetização de jovens e adultos. Campinas, SP: Autores Associados, 2011.

SOARES, Magda. Alfabetização e Letramento. São Paulo: Contexto, 2003.

SOARES, Magda. A escola como espaço de domínio da leitura e da escrita. Simpósio Internacional sobre Leitura e Escrita na Sociedade e na Escola. Brasília: Secretária de Educação Fundamental - MEC, 22 a 24 de agosto de 1994.

SOARES, Magda. Letramento e escolarização. In: RIBEIRO, Vera Masagão (Org.). Letramento no Brasil. São Paulo, $2^{a}$ edição, Global, 2004a.

SOARES, Magda. Alfabetização e letramento: caminhos e descaminhos. Pátio Revista Pedagógica. Porto Alegre: Editora Artmed, ano VIII, no 29, fev/abril 2004b.

SOARES, Magda. Novas práticas de leitura e escrita. In.: Educação e Sociedade, dossiê Letramento. São Paulo: Cortez, Revista de Ciência da Educação, vol.23, dezembro de 2002.

TFOUNI, Leda. Letramento e Alfabetização. São Paulo: Cortez, 1995.

VYGOTSKI, Lev. Concrete Human Psychology. Soviet Psychology., XXII, vol. 2. 1989. Tradução de Puzirei.

VYGOTSKI, Lev. A construção do pensamento e da linguagem. São Paulo: Martins Fontes, 2000.

Submetido em setembro de 2021

Aprovado em outubro de 2021

\section{Informações do(a)(s) autor(a)(es)}

Leila Damiana Almeida dos Santos Souza

Universidade Federal do Recôncavo da Bahia (UFRB)

E-mail: leila.damiana@ufrb.edu.br

ORCID: https://orcid.org/0000-0001-8491-2194

Link Lattes: http://lattes.cnpq.br/8966889588334706

Kleber Peixoto de Souza

Universidade Federal do Recôncavo da Bahia (UFRB)

E-mail: kleber.peixoto@ufrb.edu.br

ORCID: https://orcid.org/0000-0003-4940-1465

Link Lattes: http://lattes.cnpq.br/9315828766474222 